\title{
2010/56
}

Tradable pollution permits in dynamic general equilibrium: can optimality and acceptability be reconciled?

Thierry Bréchet, Pierre-André Jouvet and Gilles Rotillon

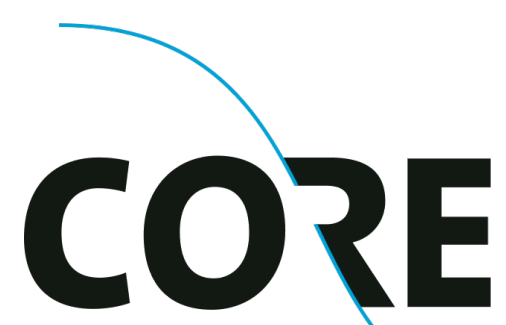

DISCUSSION PAPER

Center for Operations Research and Econometrics

Voie du Roman Pays, 34 B-1348 Louvain-la-Neuve

Belgium http://www.uclouvain.be/core 


\title{
CORE DISCUSSION PAPER \\ 2010/56
}

\section{Tradable pollution permits in dynamic general equilibrium: can optimality and acceptability be reconciled?}

\author{
Thierry BRECHET ${ }^{1}$, Pierre-André JOUVET ${ }^{2}$ \\ and Gilles ROTILLON ${ }^{3}$
}

October 2010

\begin{abstract}
In this paper we study the optimal growth path and its decentralization in a two-sector overlappinggenerations model with pollution. One sector (power generation) is polluting and the other (final good) is not. Pollution is regulated by tradable emission permits. The issue is whether the optimal growth path can be replicated in equilibrium with pollution permits, given that some permits must be issued free of charge for the sake of political acceptability. We provide a policy rule that allows optimality and acceptability to be reconciled.
\end{abstract}

Keywords: general equilibrium, optimal growth, pollution, tradable emission permits, acceptability.

JEL Classification: D61, D9, Q28

\footnotetext{
${ }^{1}$ Université catholique de Louvain, CORE and Chair Lhoist Berghmans in Environmental Economics and Management, B-1348 Louvain-la-Neuve, Belgium. E-mail: Thierry.brechet@uclouvain.be

${ }^{2}$ EconomiX, Université de Paris Ouest, Nanterre - La Défense, France.

${ }^{3}$ EconomiX, Université de Paris Ouest, Nanterre - La Défense, France.
}

The authors are grateful to the participants in the following seminars and conferences for useful preliminary discussions: CORE (Université catholique de Louvain), LERNA (University of Toulouse), Rencontres de l'Environnement (University of Lille 1), EAERE annual conference (University of Amsterdam). We also thank Hippolyte d'Albis for useful suggestions. This paper originates from a research project launched jointly with Philippe Michel.

This paper presents research results of the Belgian Program on Interuniversity Poles of Attraction initiated by the Belgian State, Prime Minister's Office, Science Policy Programming. The scientific responsibility is assumed by the authors. 


\section{Introduction}

Since Montgomery (1972) it has been well established both in the economic literature and in the policy debate that the way pollution permits are issued does not affect efficiency. This finding has been widely used in the policy debates about the carbon markets created under the Kyoto protocol, and the EU Emission Trading Scheme that came into force in 2005 (see IEA, 2005, or Ellerman et al., 2010). However, it is also well-known that this result only holds in a static setting and in partial equilibrium. In fact, very few studies have scrutinized the properties of a market for tradable permits in dynamic general equilibrium. The exception is the stream of research led by Bovenberg, Goulder and Parry on the double dividend issue (e.g. Bovenberg and De Mooij, 1994, Parry et al. 1999, Goulder, 2002). In an overlapping generation framework (OLG), ${ }^{1}$ Jouvet et al. (2005) showed that decentralization of the optimal path can be obtained with lump-sum transfers only if tradable permits are not given to the polluting firms for free. This result contrasts with the standard OLG model (Allais 1947, Diamond 1965) without environmental constraints where the optimal policy can be decentralized with lump-sum transfers without any other conditions (on this issues, see De La Croix and Michel, 2002). With an environmental externality, free permits act as a subsidy that increases the return to the owners of the firm's capital, which leads to a major distortion in the economy.

Despite the fact that the research mentioned above, by using general equilibrium models, suggest that auctioned permits or emission fees dominate the market in tradable permits with free endowment in terms of welfare, free allocation (via grandfathering) remains the main policy option in practice. This is true for the US $\mathrm{SO}_{2}$ market, the EU-ETS market, and also under the Kyoto protocol. ${ }^{2}$

Stavins (1998) explored the motives that lead policy makers to favor free allocation rather than auction, which we will call acceptability. We follow Stavins (1998) and Goulder (2002) by defining acceptability as the property that environmental regulation does not reduce a firm's profit. Clearly, if such a policy is possible, both the polluters (the firms) and the polluted (the consumer) will agree on the proposed policy. As explained by Stavins,

\footnotetext{
${ }^{1}$ Solow (1986) points out that intergenerational issues must be analyzed within an overlapping generations model which takes into account intra- and inter-generation relations.

${ }^{2}$ However, it must be noticed that political discussions on the third phase of the EUETS market led to an increase in the proportion of auctioning.
} 
existing firms favor freely allocated tradable permits because they convey rents (known in the literature as windfall profits) to them. These windfall profits create a distortion in the capital allocation among firms by increasing the total capital return, since extra profits are given to the shareholders. Furthermore, emission permits also create entry barriers since newcomers have to purchase permits from the existing firms (Koutstaal, 1997). The economic literature shows that optimality cannot be reached because it will be rejected by the polluters (here, the firms) if all the permits are auctioned. Thus, optimality and acceptability remain conflicting issues.

In this paper we question this result. By developing a two-sector overlapping generations model ${ }^{3}$ we show that the optimal path can be decentralized while satisfying the acceptability condition that firms' profits are not reduced. We provide the policy rule for that. Dynamic issues relating to the environment have long been the subject of economic analysis, especially in the framework of optimal growth models. In this framework, firms shareholders are well identified and capital accumulation can be fully studied. This is particularly important since we are interested in the effect of permit allocation on the optimal growth conditions.

The paper is organized as follows. In Section 2 the setting is presented. The optimal growth problem is laid out in Section 3, where we explicitly identify the conditions for optimal growth. In Section 4, we define a dynamic general equilibrium with pollution permits and show why giving free permits to the polluters cannot lead to optimal growth. In Section 5 we explore alternative policy solutions, and suggest a way in which optimal growth and acceptability can be reconciled. Acceptability suggests giving pollution permits for free, but optimality requires them to be fully auctioned, or an emission tax to be levied. Can the two policy options be reconciled? In section 6 , we study the long run effects of such policies. The last section is the conclusion.

\section{The model}

We model a two-sector economy. The first sector produces a good (energy, for instance) by using capital and labor and by emitting a global pollutant (carbon dioxide). The second sector produces a final good by using capital and labor, plus energy as an intermediate good. Although the final good

\footnotetext{
${ }^{3}$ Originally introduced by Galor (1992).
} 
sector uses the energy supplied by the power sector, it does not directly emit polluting emissions but, it still has an indirect effect on pollution through its energy demand to the power sector. The power sector is indexed by $e$ and the final good sector by $g$. Households consume the final good and energy, and their utility level is impacted by the quality of the environment.

\subsection{Power and final good sector technologies}

The output $Y_{t}^{g}$ of the final good sector occurs in each period according to a production function $F^{g}($.$) of capital, K_{t}^{g}$, labor, $L_{t}^{g}$ and power $Z_{t}$,

$$
Y_{t}^{g}=F^{g}\left(K_{t}^{g}, L_{t}^{g}, Z_{t}\right)
$$

The power generation sector produces an output $Y_{t}^{e}$ with a production function $F^{e}($.$) by using capital, K_{t}^{e}$, labor, $L_{t}^{e}$ and emissions $E_{t}$,

$$
Y_{t}^{e}=F^{e}\left(K_{t}^{e}, L_{t}^{e}, E_{t}\right)
$$

Both production functions are homogenous of degree one and differentiable. The power supply $Y_{t}^{e}$ will be used both as an intermediary input for the final-good sector and as a final good for consumers.

\subsection{Pollution dynamics}

Let us consider a stock pollutant whose dynamics at time $t, P_{t}$, are given by

$$
P_{t}=(1-h) P_{t-1}+m\left(E_{t}\right)
$$

where $h$ is the natural level of pollution absorption, $0 \leq h \leq 1, E_{t}$ is the flow of pollutant resulting from economic activity and $m($.$) is the contribution$ of this flow to the stock. The transition from $E_{t}$ to $m\left(E_{t}\right)$ represents the fact that only a fraction of $E_{t}$ may contribute to the flow. For example, only 95 p.c. of the flow of greenhouse gases stays in the atmosphere. With the function $m($.$) we accept that this proportion is not necessarily linearly$ related to the flow. Naturally we assume that $m_{E} \geq 0 .{ }^{4}$

\footnotetext{
${ }^{4} \mathrm{An}$ extension of this specification would be to consider abatement as an argument in the function $m($.$) . In such a case, the flow of emissions, net of abatement, that goes$ into the polluting stock would be $m(E, X)$, with $m_{X}<0$. Such a specification would not change the properties of our model. It would just introduce some more flexibility, for
} 


\subsection{Households preferences}

We consider an overlapping generation model with two consumption goods (the final good and power) and a pollution level. Individuals live for two periods. The number of agents born at date $t, N_{t}$, is exogenous. Each agent young in period $t$, supplies inelastically one unit of labor in period $t$. He or she derives utility from the consumption of the two goods during the two periods - i.e. $c_{t}^{g}$ and $c_{t}^{e}$ in period $t$ and $d_{t+1}^{g}$ and $d_{t+1}^{e}$ when old. The pollution stock negatively affects utility during the two periods of life - i.e. $P_{t}$ and $P_{t+1}$. Households preferences are thus represented by a general utility function of the form

$$
U_{t}=U\left(c_{t}^{g}, c_{t}^{e}, P_{t}, d_{t+1}^{g}, d_{t+1}^{e}, P_{t+1}\right)
$$

The function $U($.) is strictly concave, increasing with respect to the two consumption goods, and decreasing with respect to pollution, twice continuously differentiable and it satisfies the Inada conditions.

\section{Optimal growth approach}

Optimal growth is a time path of the economy that maximizes the welfare of all agents over all generations. In this section we first present the resource constraints of the economy and the optimal growth problem, and then the optimal arbitrage conditions that characterize this solution. The mathematical derivations are relegated to the Appendix.

\subsection{The optimal growth problem}

The final good sector uses capital $K_{t}^{g}$, labor $L_{t}^{g}$ and energy $Z_{t}$ as productive inputs and delivers its output to the young and old households' capital accumulation and consumption. Its resource constraint is thus,

$$
Y_{t}^{g}=F^{g}\left(K_{t}^{g}, L_{t}^{g}, Z_{t}\right)=N_{t} c_{t}^{g}+N_{t-1} d_{t}^{g}+K_{t+1}
$$

where $K_{t+1}$ is the total capital stock in the economy in the next period.

In the power sector, capital $K_{t}^{e}$, labor $L_{t}^{e}$ and emissions $E_{t}$ serve as productive inputs, and the output is used both as a final consumption good (in

example if $X$ were a policy instrument. 
both young and old age) and as an intermediate consumption good in the final good sector. The resource constraint is then written,

$$
Y_{t}^{e}=F^{e}\left(K_{t}^{e}, L_{t}^{e}, E_{t}\right)=N_{t} c_{t}^{e}+N_{t-1} d_{t}^{e}+Z_{t}
$$

We assume total depreciation of the capital stock at each period of time. Thus, the capital resource constraint implies that,

$$
K_{t}=K_{t}^{g}+K_{t}^{e}
$$

Finally, the resource constraint for labor is

$$
N_{t}=L_{t}^{g}+L_{t}^{e}
$$

We can now formulate the optimal growth problem. Let the discount factor be $\gamma, 0<\gamma<1$, and $\mathrm{U}($.$) represent the utility function as given$ by Equation (4). The optimal growth problem consists of maximizing the discounted utility given the initial value of the capital and pollution stocks $\left(K_{0}, P_{-1}\right)$, the past values for consumption for the first old, and subject to the resource constraints presented just above (Equations (5) to (8)) and to the dynamics of pollution accumulation given by Equation (3). The controls for this problem are the levels of consumption, $c_{t}^{g}, c_{t}^{e}, d_{t+1}^{g}$ and $d_{t+1}^{e}$, capital $K_{t}^{g}, K_{t}^{e}$, emissions $E_{t}$, and the intermediate consumption $Z_{t}$. Formally the problem is the following:

$$
\begin{array}{r}
\max \sum_{t=-1}^{+\infty} \gamma^{t} N_{t} U_{t} \\
\text { s.t. }\left\{\begin{array}{l}
(3),(5) \text { to }(8) \\
K_{0}, P_{-1}, d_{-1}^{g}, d_{-1}^{e}
\end{array}\right.
\end{array}
$$

The resolution of the problem is presented in the Appendix.

\subsection{Optimal arbitrage conditions}

The shadow prices associated with the physical capital stocks and the pollution stock can be eliminated from the first-order conditions. By rearranging the terms, the trade-offs faced by the central planner at the optimal solution can be explicitly written down. The three conditions, $\mathcal{C} .1, \mathcal{C} .2$ and $\mathcal{C} .3$ (below) represent the necessary conditions for optimal growth. 
Condition $\mathcal{C} .1$ - Optimal production factors allocation:

$$
\frac{1}{F_{Z_{t}}^{g}}=\frac{F_{K_{t}^{e}}^{e}}{F_{K_{t}^{g}}^{g}}=\frac{F_{L_{t}^{e}}^{e}}{F_{L_{t}^{g}}^{g}}
$$

Condition $\mathcal{C} .2$ - Trade-offs between consumptions over the life cycle:

$$
U_{c_{t}^{g}}=F_{K_{t+1}^{g}}^{g} U_{d_{t+1}^{g}} \text { and } U_{c_{t}^{e}}=F_{Z_{t}}^{g} F_{K_{t+1}^{e}}^{e} U_{d_{t+1}^{e}}=\frac{F_{Z_{t}}^{g}}{F_{Z_{t+1}}^{g}} F_{K_{t+1}^{g}}^{g} U_{d_{t+1}^{e}}
$$

Condition $\mathcal{C} .3$ - Trade-offs between the consumption of the two goods:

$$
U_{c_{t}^{e}}=F_{Z_{t}}^{g} U_{c_{t}^{g}} \text { and } U_{d_{t}^{e}}=F_{Z_{t}}^{g} U_{d_{t}^{g}}
$$

Condition $\mathcal{C} .1$ corresponds to the optimal capital and labor allocation between the two sectors. This condition implies that the ratio of the marginal productivity of capital and labor must be equal to the productivity of the intermediate good in the final sector. Condition $\mathcal{C} .2$ corresponds to the optimal consumption of the final good and the intermediate good in an individuals life-cycle. The intertemporal consumption of final good is determined by the marginal productivity of capital in this sector and the intertemporal consumption of energy depends on the marginal productivity variation of the intermediate good. Condition $\mathcal{C} .3$ corresponds to the optimal division of consumption between the final good and the intermediate good within a period. The ratio of the marginal utilities of consumption are proportional to the marginal productivity of the intermediate good in the final sector.

Indeed, all the conditions imply a proportionality with the marginal productivity of the intermediate good in the final sector. This comes from the fact that the intermediate good is the only direct link between the two sectors. Therefore, combining Conditions $\mathcal{C} .1, \mathcal{C} .2$ and $\mathcal{C} .3$ provides us with the following synthetic condition:

$$
\frac{1}{F_{Z_{t}}^{g}}=\frac{F_{K_{t}^{e}}^{e}}{F_{K_{t}^{g}}^{g}}=\frac{F_{L_{t}^{e}}^{e}}{F_{L_{t}^{g}}^{g}}=\frac{U_{c_{t}^{g}}}{U_{c_{t}^{e}}^{e}}=\frac{U_{d_{t}^{g}}}{U_{d_{t}^{e}}^{e}}=\frac{F_{Z_{t+1}}^{g}}{F_{Z_{t}}^{g}} \frac{U_{d_{t+1}^{g}}}{U_{d_{t+1}^{e}}}
$$

This synthetic condition stresses the proportionality between capital allocation, labor, first and second period consumption, intertemporal consumption and the marginal productivity of intermediate good in the final sector. If one 
of these conditions does not hold then the equilibrium is suboptimal.

\section{Pollution regulation with pollution permits}

Let us now turn to the dynamic general equilibrium of the economy. All markets are assumed to be competitive. The output of the final good sector is the numeraire and the energy price is denoted by $p_{t}^{e}$. In this section we shall first describe the behavior of agents (the government, households, and firms) and then the general intertemporal equilibrium of the economy. Comparing the equilibrium solution when pollution is regulated with tradable permits with the optimal growth solution will yield our first result.

\subsection{The government}

The government is endowed with two policy instruments. It can regulate pollution with a market for tradable emission permits, and it can manage transfers among households. Let us explain the functioning of these policy instruments.

Pollution is regulated by means of a market for tradable emission permits à la Montgomery (1972). An amount of emission permits is issued to each firm by the regulator, each permit allowing for a unitary emission level. Then, firms are allowed to trade these permits among themselves on a market. It is assumed throughout this paper that the government issues a number of permits $\bar{E}_{t}$ that coincides with the global optimal pollution level, $\bar{E}_{t}=E_{t}^{\star}$. In order to be as general as possible we consider that two issuing methods can be implemented by the government: free endowment and auctioning. $\bar{E}_{t}^{e}$ $\left(0 \leq \bar{E}_{t}^{e} \leq \bar{E}_{t}\right)$ are allocated for free to the polluting firms, and the remainder, $\bar{E}_{t}-\bar{E}_{t}^{e}$, are auctioned. The price of a pollution permit is denoted by $q_{t}$.

As in any OLG model the government can also organize lump-sum transfers to households, with $\tau_{t}$ being associated with the young agent and $\theta_{t}$ with the old agent. Considering the second welfare theorem, in the standard OLG model (without externalities) these transfers allow the government to achieve any Pareto-optimal allocation (see Atkinson and Sandomo, 1980, Sala-i-Martin, 1996, or De La Croix and Michel, 2002).

The governmental budget constraint then reads as follows,

$$
N_{t} \tau_{t}+N_{t-1} \theta_{t}=q_{t}\left(\bar{E}_{t}-\bar{E}_{t}^{e}\right)
$$




\subsection{Households consumption and savings}

Households take the environmental quality as given. At the first period of life, the young agent earns the wage $w_{t}$ and receives a transfer $\tau_{t}$ which may be positive or negative. He or she consumes the final good and energy, $c_{t}^{g}$ and $c_{t}^{e}$, and saves $s_{t}$. Thus, the first period budget constraint is,

$$
w_{t}+\tau_{t}=c_{t}^{g}+p_{t}^{e} c_{t}^{e}+s_{t}
$$

When old, after retirement, the agent receives a transfer $\theta_{t+1}$ in addition to any return on savings, $\Omega_{t+1} s_{t}$, where $\Omega_{t+1}$ is the return factor on savings. The old agent uses all his or her income to consume $d_{t+1}^{g}$ and $d_{t+1}^{e}$. The second period budget constraint is thus

$$
d_{t+1}^{g}+p_{t+1}^{e} d_{t+1}^{e}=\Omega_{t+1} s_{t}+\theta_{t+1}
$$

The representative household maximizes its utility (4) by choosing consumption subject to the budget constraints (14) and (15). Given prices and pollution levels, $P_{t}$ and $P_{t+1}$, the first-order conditions of arbitrage between the two goods are,

$$
\begin{gathered}
p_{t}^{e} U_{c_{t}^{g}}=U_{c_{t}^{e}} \\
p_{t+1}^{e} U_{d_{t+1}^{g}}=U_{d_{t+1}^{e}}
\end{gathered}
$$

and the intertemporal arbitrage between the young and old age groups leads to

$$
U_{c_{t}^{g}}=\Omega_{t+1} U_{d_{t+1}^{g}} \text { and } U_{c_{t}^{e}}=\frac{p_{t}^{e}}{p_{t+1}^{e}} \Omega_{t+1} U_{d_{t+1}^{e}}
$$

Relations (16) and (17) give the trade-offs between the consumption of the final good and energy. Relation (18) gives the trade-off between consumption over the agent's life cycle.

\subsection{Representative firms behaviour}

Like Galor (1992), we consider a representative firm in each sector, operating under perfect competition. At time $t$ the capital stocks of the two sectors, $K_{t}^{g}$ and $K_{t}^{e}$, are given by $t-1$ savings decisions. We assume that capital fully depreciates after one period. ${ }^{5}$ The firms take prices $w_{t}, p_{t}^{e}$ and $q_{t}$ as

\footnotetext{
${ }^{5}$ The qualitative nature of our results would not be altered by the assumption of partial depreciation.
} 
given and maximize their net revenue.

The representative firm in the final good sector maximizes $F^{g}\left(K_{t}^{g}, L_{t}^{g}, Z_{t}\right)-$ $w_{t} L_{t}^{g}-p_{t}^{e} Z_{t}$ with respect to $L_{t}^{g}$ and $Z_{t}$. The first-order conditions are,

$$
\begin{aligned}
& F_{L_{t}^{g}}^{g}\left(K_{t}^{g}, L_{t}^{g}, Z_{t}\right)=w_{t} \\
& F_{Z_{t}}^{g}\left(K_{t}^{g}, L_{t}^{g}, Z_{t}\right)=p_{t}^{e}
\end{aligned}
$$

In the final good sector the capital return is given by $\Omega_{t}^{g}=\pi_{t}^{g} / K_{t}^{g}$, where $\pi_{t}^{g}$ is the profit. From the Euler equation, this is equal to the marginal productivity of capital, i.e. $\Omega_{t}^{g}=F_{K_{t}}^{g}\left(K_{t}^{g}, L_{t}^{g}, Z_{t}\right)$.

In the power sector, by taking $K_{t}^{e}$ and $\bar{E}_{t}^{e}$ as given, the representative firm maximizes $p_{t}^{e} F^{e}\left(K_{t}^{e}, L_{t}^{e}, E_{t}\right)-w_{t} L_{t}^{e}-q_{t}\left(E_{t}-\bar{E}_{t}^{e}\right)$. The first-order conditions are,

$$
\begin{aligned}
& F_{L_{t}^{e}}^{e}\left(K_{t}^{e}, L_{t}^{e}, E_{t}\right)=\frac{w_{t}}{p_{t}^{e}} \\
& F_{E_{t}}^{e}\left(K_{t}^{e}, L_{t}^{e}, E_{t}\right)=\frac{q_{t}}{p_{t}^{e}}
\end{aligned}
$$

Consequently, the capital return in the power sector $\Omega_{t}^{e}=\pi_{t}^{e} / K_{t}^{e}$ is

$$
\Omega_{t}^{e}=p_{t}^{e} F_{K_{t}^{e}}^{e}+q_{t} \frac{\bar{E}_{t}^{e}}{K_{t}^{e}}
$$

Profits per unit of capital represent the return on investment that is given to the shareholder, i.e. the owner of the capital stock. In our model, the owner of the capital stock is the household when old. These first-order conditions show that the capital return in the power sector is determined not only by the marginal productivity of capital, but also by the market value of the free endowment of pollution permits given to the firm (the free endowment valued at the market price of emission permits). This last term represents the so-called windfall profit (for a discussion about windfall profits, see e.g. Verbruggen, 2008).

The very existence of a windfall profit can alternatively be shown by considering a firm which maximizes the following profit function, where an endowment of permits explicitly appears,

$$
\pi_{t}^{e}=p_{t}^{e} F^{e}\left(K_{t}^{e}, L_{t}^{e}, E_{t}\right)-w_{t} L_{t}^{e}-R_{t}^{e} K_{t}^{e}-q_{t}\left(E_{t}-\bar{E}_{t}^{e}\right)
$$

where $R_{t}^{e}$ stands for market capital return. The first-order condition for 
a firm's capital demand is $F_{K_{t}^{e}}^{e}\left(K_{t}^{e}, L_{t}^{e}, E_{t}\right)=R_{t}^{e} / p_{t}^{e}$. By using the Euler condition the windfall profit of $q_{t} \bar{E}_{t}^{e}$ is obtained explicitly.

It can also be seen that, if all the permits were auctioned instead of being allocated for free, then regulation with tradable emission permits would be strictly equivalent to regulation with an emission fee. On the other hand, a simple command-and-control regulation would not generate such windfall profit. So the debate is not only about quantity versus price regulation, it is also about the assignment of the property rights on the pollution to economic agents. With free emission permits, the rent is given to the firms, which distort the capital market. This adverse effect would not appear with price or command-and-control regulations.

The fact that capital return in the power sector depends on both the marginal productivity of capital and on the market value of the free endowment of pollution permits deserves some more attention. One way, anticipating somewhat the equilibrium analysis that will be conducted in the next section, is to understand the microeconomic rational of the capital supplier in the presence of a free endowment of permits. In our model capital is supplied by the agents in their old age. The amount of saving supplied $s_{t}$ comes from the first-order condition (18). Given that the agent's objective is to maximize the return to savings by allocating it optimally between the two productive sectors, this problem can be formulated as a portfolio problem. Let us denote by $\alpha_{t}$ the proportion of savings invested in the final good sector, $\left(1-\alpha_{t}\right)$ being the share invested in the power sector. In a portfolio approach the agent's problem consists of maximizing the capital return for a given level of savings, which is written as follows, for all $t$,

$$
\max _{\left\{\alpha_{t}\right\}} s_{t}\left(\alpha_{t} F_{K_{t}^{g}}^{g}+\left(1-\alpha_{t}\right)\left(p_{t}^{e} F_{K_{t}^{e}}^{e}+q_{t} \frac{\bar{E}_{t}^{e}}{K_{t}^{e}}\right)\right)
$$

Meeting the first-order condition for this problem at time $t$ directly yields the optimal arbitrage condition:

$$
F_{K_{t}^{g}}^{g}=p_{t}^{e} F_{K_{t}^{e}}^{e}+q_{t} \frac{\bar{E}_{t}^{e}}{K_{t}^{e}}, \forall t
$$

which corresponds to relation (23) with equality between the two sector capital returns (as we will see in the next section). 


\subsection{Intertemporal general equilibrium}

The intertemporal equilibrium is defined for a given sequence of government decisions $\left\{\tau_{t}, \theta_{t}, \bar{E}_{t}, \bar{E}_{t}^{e}\right\}$ satisfying the government budget constraint given by Equation (13). It is a sequence of prices $\left\{p_{t}^{e}, w_{t}, q_{t}\right\}$, individual variables $\left\{c_{t}^{g}, c_{t}^{e}, s_{t}, d_{t+1}^{g}, d_{t+1}^{e}\right\}$ and aggregate variables $\left\{K_{t}^{g}, L_{t}^{g}, Z_{t}, Y_{t}^{g}\right\},\left\{K_{t}^{e}, L_{t}^{e}\right.$, $\left.E_{t}, Y_{t}^{e}\right\}, P_{t}$ and $K_{t+1}$, satisfying all the equilibrium conditions. Households maximize their utility and each firm maximizes its profit. A necessary condition for equilibrium in the capital market is the equality of capital returns between the two sectors, $\Omega_{t}^{g}=\Omega_{t}^{e}=\Omega_{t}$. The total capital stock is equal to savings i.e. $K_{t}^{g}+K_{t}^{e}=K_{t}=N_{t-1} s_{t-1}$. All markets (labor, capital, pollution permits, energy and final good) clear. The dynamical equation for the environment holds. The first old agent, born at time $t-1$, satisfies the budget constraint and the optimal trade-off conditions,

$$
p_{0}^{e} d_{0}^{e}+d_{0}^{g}=\Omega_{0} s_{-1}+\theta_{0} \text { and } U_{d_{0}^{g}}=p_{0}^{e} U_{d_{0}^{e}}
$$

and the initial capital stock $K_{0}=N s_{-1}$ is given. We can now explicitly define the equilibrium of the economy when labor and capital are perfectly mobile across sectors.

\section{Definition 1 Intertemporal general equilibrium}

For a given policy $\left\{\bar{E}_{t}, \bar{E}_{t}^{e}, \tau_{t}, \theta_{t}\right\}_{t \geq 0}$ an equilibrium is defined by

- a sequence of prices $\left\{q_{t}, p_{t}^{e}, w_{t}\right\}_{t \geq 0}$ and capital returns $\left\{\Omega_{t}\right\}_{t \geq 0}$,

- a sequence of individuals variables $\left\{c_{t}^{g}, c_{t}^{e}, s_{t}, d_{t+1}^{g}, d_{t+1}^{e}\right\}_{t \geq 0}$ satisfying Relations (14) to (18), and $d_{0}^{g}$ and $d_{0}^{e}$ satisfying Relation (24),

- a sequence of aggregate variables $\left\{K_{t}^{g}, L_{t}^{g}, Z_{t}, Y_{t}^{g}\right\}_{t \geq 0},\left\{K_{t}^{e}, L_{t}^{e}, E_{t}, Y_{t}^{e}\right\}_{t \geq 0}$, $\left\{P_{t}\right\}_{t \geq 0}$ and $\left\{K_{t+1}\right\}_{t \geq 0}$ satisfying Equations (19) to (23),

such that, $\forall t \geq 0$, the following equilibrium conditions hold:

- the government budget (13) is balanced,

- the capital stock $K_{t}=K_{t}^{g}+K_{t}^{e}$ is equal to savings $N_{t-1} s_{t-1}$, with $K_{t}^{g}$ and $K_{t}^{e}$ such that $\Omega_{t}^{g}=\Omega_{t}^{e}$, 
- markets for labor, final good, power, and tradable permits clear, i.e.: $L_{t}^{g}+L_{t}^{e}=N_{t}$,

$Y_{t}^{g}=F^{g}\left(K_{t}^{g}, L_{t}^{g}, Z_{t}\right)=N_{t} c_{t}^{g}+N_{t-1} d_{t}^{g}+K_{t+1}$,

$Y_{t}^{e}=F^{e}\left(K_{t}^{e}, L_{t}^{e}, E_{t}\right)=N_{t} c_{t}^{e}+N_{t-1} d_{t}^{e}+Z_{t}$,

$\bar{E}_{t}=E_{t}^{\star}=E_{t}$

- the dynamics of pollution follow Equation (3).

We are now equipped to state the first result of this paper, which is that giving free emission permits to the polluting firms prevents the economy from following an optimal growth path.

Proposition 1 For any policy $\left\{\bar{E}_{t}, \bar{E}_{t}^{e}, \tau_{t}, \theta_{t}\right\}_{t \geq 0}$ such that $\bar{E}_{t}=E_{t}^{*}, \bar{E}_{t}^{e}>0$, and $q_{t}>0, \forall t \geq 0$, optimality Condition $\mathcal{C} .1$ is not satisfied in equilibrium.

Proof. In equilibrium the condition of equal capital return in both sectors is

$$
\frac{\pi_{t}^{g}}{K_{t}^{g}}=\frac{\pi_{t}^{e}}{K_{t}^{e}} \Leftrightarrow F_{K_{t}^{g}}^{g}=p_{t}^{e} F_{K_{t}^{e}}^{e}+q_{t} \frac{\bar{E}_{t}^{e}}{K_{t}^{e}}
$$

This, along with Equation (20), implies that

$$
\frac{\pi_{t}^{g}}{K_{t}^{g}}=\frac{\pi_{t}^{e}}{K_{t}^{e}} \Leftrightarrow F_{K_{t}^{g}}^{g}=F_{Z_{t}}^{g} F_{K_{t}^{e}}^{e}+q_{t} \frac{\bar{E}_{t}^{e}}{K_{t}^{e}}
$$

which departs from the optimality Condition $\mathcal{C} .1$.

It appears that allocating free permits is equivalent to increasing the capital return in the polluting sector. This sector then becomes artificially more productive than the final good sector, thus attracting more capital than it should from a social optimum standpoint. This also characterizes an equilibrium à la Hahn and Solow (1997) in terms of gross operating surplus. Note, however, that, in equilibrium, the pollution level matches the optimal one, because the number of permits issued by the government is optimal by assumption.

It is interesting to notice that, in equilibrium, the two other optimality Conditions, $\mathcal{C} .2$ and $\mathcal{C}$.3, are met. This can be checked for the trade-off between consumption over the life cycle (Condition $\mathcal{C}$.2) by combining Relation (18), firms optimization conditions, and the equilibrium condition on capital 
allocation, i.e. the equality of capital returns between the two sectors. This yields,

$$
U_{c_{t}^{g}}=F_{K_{t+1}^{g}}^{g} U_{d_{t+1}^{g}} \text { and } U_{c_{t}^{e}}=\frac{F_{Z_{t}}^{g}}{F_{Z_{t+1}}^{g}} F_{K_{t+1}^{g}}^{g} U_{d_{t+1}^{e}}
$$

which corresponds to the optimality condition. It is straightforward to see that the trade-offs between the consumption of the two goods (Condition $\mathcal{C} .3$ ) is also satisfied. Naturally, Relation (12) cannot be satisfied, because

$$
\frac{F_{K_{t}^{e}}^{e}}{F_{K_{t}^{g}}^{g}}=\frac{F_{L_{t}^{e}}^{e}}{F_{L_{t}^{g}}^{g}}-\frac{q_{t}}{F_{K_{t}^{g}}^{g}} \frac{\bar{E}_{t}^{e}}{F_{L_{t}^{g}}^{g}}
$$

Hence, Proposition 1 shows that giving permits for free to the polluting firms does not allow pollution to be regulated optimally, even though the market for tradable permits itself works fine. Even though this idea is wellestablished in the literature (see the Introduction, above), the theoretical rational for it is far from straightforward. In our setting it clearly appears that free-permit endowment generates some windfall profits to polluters that distort the capital market, yielding too much capital accumulation in the polluting sector. This is the dynamic general equilibrium setting that allows this property to be highlighted.

Before demonstrating how to restore optimality the following lemma is required. It shows that, provided an adequate public policy is in place, the optimal path is an equilibrium.

Lemma 1 The optimal path $\left\{c_{t}^{g}, c_{t}^{e}, d_{t}^{g}, d_{t}^{e}, K_{t}^{g}, L_{t}^{g}, Z_{t}, E_{t}, P_{t}, K_{t+1}\right\}_{t \geq 0}$ is an equilibrium with public decisions $\bar{E}_{t}=E_{t}^{\star}, \tau_{t}=c_{t}^{g}+p_{t}^{e} c_{t}^{e}+s_{t}-w_{t}$ and $\theta_{t}=d_{t}^{g}+p_{t}^{e} d_{t}^{e}-\Omega_{t} s_{t}$, where $p_{t}^{e}=1 / F_{Z_{t}}^{g}, w_{t}=F_{L_{t}^{g}}^{g}, \Omega_{t}=F_{K_{t}^{g}}^{g}, q_{t}=F_{E_{t}}^{e} F_{Z_{t}}^{g}$ and $s_{t}=K_{t+1} / N_{t}$.

This lemma corresponds to the second fundamental theorem of welfare economics. Proving this lemma is straightforward. It is sufficient to check that all intertemporal equilibrium conditions are satisfied. Then, any path satisfying the resource constraints of the economy and the optimality Conditions $\mathcal{C} .1, \mathcal{C} .2$ and $\mathcal{C} .3$ is an equilibrium. 


\section{How to restore optimality conditions}

Let us consider that, as throughout the paper, the government manages polluting emissions with tradable pollution permits, and let us also assume that some of these may be give for free (for example on grounds of acceptability). The question raised in this section is whether it is possible to find an allocation rule of permits such that optimality conditions are fulfilled. Our purpose is to ask whether such a rule exists even when some permits are given for free.

\subsection{No free permits}

The first way to restore optimality Conditions $\mathcal{C} .1, \mathcal{C} .2$ and $\mathcal{C} .3$ appears naturally from Proposition 1. It simply consists of not giving free permits to the polluters. This is what Proposition 2 states:

Proposition $2 A$ policy $\left(\bar{E}_{t}, \bar{E}_{t}^{e}, \tau_{t}, \theta_{t}\right)_{t \geq 0}$ such that $\bar{E}_{t}=E_{t}^{*}$ and $q_{t}>0$ replicates the optimal solution in intertemporal equilibrium if $\bar{E}_{t}^{e}=0, \forall t \geq 0$.

Proof. The equilibrium condition

$$
\frac{\pi_{t}^{g}}{K_{t}^{g}}=\frac{\pi_{t}^{e}}{K_{t}^{e}} \Leftrightarrow F_{K_{t}^{g}}^{g}=F_{Z_{t}}^{g} F_{K_{t}^{e}}^{e}+q_{t} \frac{\bar{E}_{t}^{e}}{K_{t}^{e}}
$$

coincides with the optimality condition $\mathcal{C} .1$ if $\bar{E}_{t}^{e}=0$.

In other words, permits should be fully auctioned and not allocated for free to the polluting firms. As soon as some free permits are given out, albeit even a small proportion, the whole economy departs from the optimal path. This result confirms, in the more general setting of a two-sector economy and with general specifications, the result of Jouvet et al. (2005). The fact that the market for permits has an impact on the whole economy through intermediate consumption in the final-good sector does not alter this result.

The next subsection proposes another solution, where regulation policy allows that, on grounds of acceptability, some of the pollution permits must be issued for free. 


\subsection{Pollution permits for all}

The sectoral dimension of our model allows us to investigate another solution for restoring the optimality condition in capital allocation. If the aim is to ensure equal capital returns in both productive sectors, then it is immediately obvious that giving permits to both sectors would solve the problem. Let us denote by $\bar{E}_{t}^{g}$ the number of free permits that are given to firms in the final-good sector. We assume that the total endowment of permits in the economy, $\bar{E}_{t}$, is the optimal one, and that a fraction of this endowment, $\bar{E}_{t}^{e}+\bar{E}_{t}^{g} \leq \bar{E}_{t}=E_{t}^{*}, \forall t \geq 0$, is allocated free of charge. This second solution flows directly from the proof of Proposition 1 and it is expressed in the following lemma.

Lemma 2 Under a policy $\left(\bar{E}_{t}, \bar{E}_{t}^{e}, \bar{E}_{t}^{g}, \tau_{t}, \theta_{t}\right)_{t \geq 0}$ such that $\bar{E}_{t}=E_{t}^{*}, \bar{E}_{t}^{e}>0$, $\bar{E}_{t}^{g}>0$, and $q_{t}>0, \forall t \geq 0$, the optimality Condition $\mathcal{C} .1$ is satisfied if

$$
\frac{\bar{E}_{t}^{e}}{K_{t}^{e}}=\frac{\bar{E}_{t}^{g}}{K_{t}^{g}}
$$

Proof. The general equilibrium with free permits $\bar{E}_{t}^{g}>0$ and $\bar{E}_{t}^{e}>0$ allocated to the two sectors results in

$$
F_{K_{t}^{g}}^{g}+q_{t} \frac{\bar{E}_{t}^{g}}{K_{t}^{g}}=F_{Z_{t}}^{g} F_{K_{t}^{e}}^{e}+q_{t} \frac{\bar{E}_{t}^{e}}{K_{t}^{e}} \Leftrightarrow F_{K_{t}^{g}}^{g}=F_{Z_{t}}^{g} F_{K_{t}^{e}}^{e}+q_{t}\left(\frac{\bar{E}_{t}^{e}}{K_{t}^{e}}-\frac{\bar{E}_{t}^{g}}{K_{t}^{g}}\right)
$$

Thus, the optimality Condition $\mathcal{C} .1$ is fulfilled if $\frac{\bar{E}_{t}^{e}}{K_{t}^{e}}=\frac{\bar{E}_{t}^{g}}{K_{t}^{g}}, \forall q_{t}$.

This lemma shows that, by giving a sufficient number of free permits to all firms, dynamics conditions on capital allocation among sectors can be restored. Because the final good sector does not pollute, giving it some pollution permits is equivalent to giving it a lump-sum transfer. Importantly, this transfer is valued at the market price of tradable permits in equilibrium, which coincides with the optimal pollution price because the emission cap is equal to the socially optimal emission level. It can easily be checked that equilibrium does not depend on the proportion of permits that are given for free.

This sharing rule is a dynamic one. The balance between the two sectors must be determined in each time period such that the lump-sum transfer is similar in terms of capital units. 
The fact that polluting permits are given to firms which do not pollute may seem somewhat puzzling. Actually, this is less paradoxical than it seems at first sight. The rational for such a measure is twofold:

1. cost pass through: the final good sector bears a cost because the power sector increases its output price when the price of carbon increases in the market for tradable permits; so some compensation should be given to these firms;

2. fairness: if a lump sum is to be given to some firms, which increases their market value (the power sector), then it should also be given to all other firms in the economy.

\subsection{Restoring optimal growth}

Lemma 2 states that optimality Condition $C 1$ can be restored, which was not the case when permits were given only to the polluting firms. Under the allocation rule given in Lemma 2, given the equality of capital returns, Relation (18) now becomes

$$
U_{c_{t}^{g}}=\left(F_{K_{t+1}^{g}}^{g}+q_{t+1} \frac{\bar{E}_{t+1}^{g}}{K_{t+1}^{g}}\right) U_{d_{t+1}^{g}} \text { and } U_{c_{t}^{e}}=\frac{p_{t}^{e}}{p_{t+1}^{e}}\left(F_{K_{t+1}^{g}}^{g}+q_{t+1} \frac{\bar{E}_{t+1}^{g}}{K_{t+1}^{g}}\right) U_{d_{t+1}^{e}}
$$

with the households' trade-off between the two goods (16) and (17), and firms' optimization Conditions (19), (20) and (21). Condition $\mathcal{C} .3$ also holds. This ensures that Relation (12) is also true. Then, we obtain the optimal proportion of consumption, and we only have to restore the optimal level of consumptions, which can be done with adequate transfers between young and old at each time period. This result is summarized in Proposition 3.

Proposition 3 Using Lemmas 1 and 2, optimal growth can be replicated in equilibrium, provided an adequate fiscal policy, $\tau_{t}$ and $\theta_{t}$.

\subsection{Long-term equilibrium analysis}

It is interesting to explore how the equilibrium is affected by the allocation of permits. We shall conduct this analysis on the long-term steady-state equilibrium. As a starting point we compute the optimal solution at the steady state and consider a regime with no free permits. In this case, it is well 
known that environmental regulation with pollution permits is equivalent to regulation with a tax on emission. At the steady state, the output in the final-good sector is given by

$$
Y^{g}=F^{g}\left(K^{g}, L^{g}, Z\right)
$$

and the power generation sector produces,

$$
Y^{e}=F^{e}\left(K^{e}, L^{e}, E\right)
$$

The pollution level is given by

$$
P=\frac{m(E)}{h}
$$

The resource Constraints (5) and (6) are respectively,

$$
Y^{g}=F^{g}\left(K^{g}, L^{g}, Z\right)=N c^{g}+N d^{g}+K
$$

and

$$
Y^{e}=F^{e}\left(K^{e}, L^{e}, E\right)=N c^{e}+N d^{e}+Z
$$

Thus, with non-negative variables the problem can be written as:

$$
\begin{gathered}
\max N U\left(c_{t}^{g}, c_{t}^{e}, P_{t}, d_{t+1}^{g}, d_{t+1}^{e}, P_{t+1}\right) \\
\text { s.t. }\left\{\begin{array}{l}
(27),(28),(29) \\
K=K^{g}+K^{e}, N=L^{g}+L^{e}
\end{array}\right.
\end{gathered}
$$

Solving this problem leads to Conditions similar to $\mathcal{C} .1, \mathcal{C} .2$ and $\mathcal{C} .3$, where $F_{K^{g}}^{g}=1$ (which corresponds to the golden rule) and $F_{E}^{e}=-2 N \frac{U_{P}}{U_{c} e} \frac{m_{E}}{h}$ (which defines the optimal emission level). Then, consumption levels for the two goods are given by $U_{c^{g}}=U_{d^{g}}=U_{c^{e}} / F_{Z}^{g}$, and $U_{c^{e}}=F_{Z}^{g} F_{K^{e}}^{e} U_{d^{e}}$. Because labor and capital are perfectly mobile across sectors, we have $F_{K^{\star g}}^{g}=F_{Z}^{g} F_{K^{\star e}}^{e}=1$. Therefore, at the optimal steady state all marginal utilities of consumption are equalized. Without an endowment of free permits the golden rule could be reached in a decentralized way by introducing a stock of pollution permits $\bar{E}=E^{\star}$ such that $q^{\star}=-2 N \frac{U_{P^{\star}}}{U_{c^{\star \star}}} \frac{m_{E^{\star}}}{h} .6$

\footnotetext{
${ }^{6}$ Symmetrically, the golden rule could be reached by introducing a tax $\tau=$ $-2 N \frac{U_{P^{\star}}}{U_{c^{e \star}}} \frac{m_{E^{\star}}}{h}$ on emissions.
} 
Let us now examine the two alternative solutions. First, we consider the case where pollution permits, $\bar{E}^{e}$, are given to the power sector free of charge. As explained above, this generates a windfall profit and increases the return on capital, $\Omega=F_{Z}^{g} F_{K^{e}}^{e}+q \frac{\bar{E}^{e}}{K^{e}}$. Because of the optimality conditions and perfect mobility of production factors, it implies that, in equilibrium, $F_{\hat{K}^{g}}^{g}=1>F_{Z}^{g} F_{\hat{K}^{e}}^{e}$. So there is a distortion in capital allocation between the two sectors. This distortion leads to more capital in the power sector than in the final-good sector at equilibrium, $\hat{K}^{e}>K^{\star e}$. In order to keep $F_{\hat{K}^{g}}^{g}=1$, the capital stock is larger than what it would be under the golden rule, and thus the life-cycle consumption level is lower. Moreover, the optimal arbitrage between consuming energy and the final good, i.e. $U_{c^{e}} \neq U_{d^{e}}$, cannot be fulfilled since $F_{Z}^{g} F_{K^{e}}^{e}<1$. Therefore, there is no lump-sum transfer rule between old and young that could restore the golden rule.

Let us now turn to the case where free permits are allocated to both sectors according to the allocation rule defined in Lemma $2, \bar{E}^{e} / K^{e}=\bar{E}^{g} K^{g}$. We already know that, under this rule, all optimal trade-offs are satisfied (in particular the equality of marginal productivity between the two sectors, $F_{\tilde{K}^{g}}^{g}=F_{Z}^{g} F_{\tilde{K}^{e}}^{e}$, and the equality of marginal utilities of consumption goods). In this case, the trouble comes from the fact that there is an excess capital accumulation, because $F_{\tilde{K}^{g}}^{g}=F_{Z}^{g} F_{\tilde{K}^{e}}^{e}<1$. The main difference with the previous case is that the distortion caused by the free-permit allocation is now symmetric between the sectors. What needs to be corrected is the overaccumulation of capital. A standard implication of optimality condition is that a steady state with over-accumulation of capital is not Pareto-optimal in terms of consumption level. At least one date, it is possible to increase total consumption by reducing the capital stock without reducing consumption at any other date. Samuelson (1975) showed that lump-sum transfers can lead a stationary economy to the golden rule. In our case, the steady state is larger than the golden rule, which indicates over-accumulation. Thus, the optimal transfer is a positive one to the older household. With this kind of transfer, the golden rule can be restored. Therefore, giving permits to all productive sectors, with transfers among households, induces an increase in consumption, and thus an increase in profits in the final-good sector. 


\section{Back to acceptability}

The question of the impact of such a policy on the profits of the polluting sector remains open. This is the subject of this final section. Proposition 3 (above) shows that it is possible to restore optimal growth even when free emission permits are given for issued, provided the endowment follows the policy rule given in Lemma 2. Still, Proposition 3 says nothing about acceptability, understood in the sense of Stavins (1998). So the question of whether or not acceptability and optimality can be reconciled remains open. This is the empirical question we want to address in this section.

Let us first come back return to the policy rule of in Lemma 2. It is clear that giving some permits for free to the polluters opens the door to possible compensations recompense for abatement efforts, and thus for a non-decrease to a maintenance of in profits. On that basis, it is easy to see that there may exist some policy configurations in which both acceptability and optimality could be met.

Let us now consider the most generous case where the government issues all permits for free of charge (thus, giving up renouncing the possibility to of raising some revenue through an auction). We assume that the endowments follow the rule provided in Lemma 2. The polluting sector is thus endowed with a windfall profit given by of $q_{t} \bar{E}_{t}^{e}$. Still, the polluting sector then will buy all the permits that have been given to the non-polluting sector, i.e. $q_{t} \bar{E}_{t}^{g}$. Let us assume, for the sake of argument, that both sectors are the same size, that is, $K_{t}^{e}=K_{t}^{g}$. Then it is obvious that the windfall profit provided to the power sector will exactly compensate for the number of permits the power sector will have to purchase from the final-good sector. So purchasing the permits will be financed by the windfall profit. Nevertheless, because the emission cap is binding, the power sector still bears an abatement cost. So its profit level will be reduced by the environmental regulation. ${ }^{7}$

This rationale can be used in the following way. Assume that the actual size of the polluting sector is large enough for its purchase of permits from the non-polluting sector to be small in comparison with its abatement cost, net of the windfall profit. The polluting sector will then experience a profit increase with the environmental regulation. Thus, Stavins' acceptability criterion will

\footnotetext{
${ }^{7}$ Providing the polluting sector with more permits than its pollution level would create 'hot air', but it would imply that the emission cap in the final good sector is more stringent, because we assume that the global emission cap is the optimal one. So, such a scenario would not change the story.
} 
be met.

The condition of a large polluting sector in comparison with the nonpolluting sector seems to be met in the EU-ETS carbon market. The carbonemitters sector is much larger than the non-emitters. Non-emitters are essentially only the residential sector using only electricity. All other economic sectors (agriculture, industry, transport) emit some carbon. So, in practice, it would probably not be too difficult to cope with the problem of the capital-market distortion raised by Proposition 1.

The issue of the accompanying fiscal policy also deserves to be discussed. Restoring optimal growth requires an adequate fiscal policy in terms of $\theta$ and $\tau$. To restore the optimal arbitrage between consumption and savings the government can levy a tax on savings and redistribute it to the young, or organize transfers among households. Realistically, this means that the capital returns associated with the windfall profits are redistributed optimally among the households. It must be noted that what is taxed is not the windfall profit itself but its return in the capital market. This also means that, depending on the optimality criteria used, the redistribution rule leading to optimal values for $\tau_{t}$ and $\theta_{t}$, may vary. An important policy implication of this result is that tradable emission permits (issued free of charge) should not be considered as substitutes for fiscal policies as is usually the case in the literature. ${ }^{8}$ Free permits might issued on the grounds of the Stavins' acceptability argument that "firms should not be worse-off", but permits must be accompanied by an adequate fiscal policy on factor income. In other words, quantity- and price-based regulation should be combined in order to reach optimal growth and political acceptability. They are complements, not substitutes.

\section{Conclusion}

The purpose of this paper was to question the idea that political acceptability and optimality are conflicting goals in the field of pollution control. We have modeled a two-sector dynamic general equilibrium economy in which a global pollutant is regulated with tradable emission permits, some of which are allocated free if charge for the sake of acceptability. Our main results are that optimal growth can be replicated even when some permits are given

\footnotetext{
${ }^{8}$ See the voluminous debate in environmental economics on quantity vs. price regulation initiated by Weitzman (1974).
} 
for free, but this requires two conditions: $(i)$ permits must be given to all firms following a given sharing rule (provided in the paper), and ( $i i$ ) the windfall profits must be redistributed among agents using an adequate fiscal policy. This first result shows that quantity-based regulation and price regulation are best used in concert, not as substitutes. Second, acceptability à la Stavins (1998) can be combined with optimal growth if the polluting sector is substantially larger than the non-polluting sector. In this case, the windfall profits given to the polluters will be large enough to compensate for the pollution abatement costs and for the purchase of permits from the non-polluting sector.

\section{Appendix: The optimal growth problem}

The optimal growth problem presented in Section 3.1 will be solved in this appendix. The problem is:

$$
\begin{gathered}
\max \sum_{t=-1}^{+\infty} \gamma^{t} N_{t} U_{t} \\
\text { s.t. }\left\{\begin{array}{l}
(3),(5) \text { to }(8) \\
K_{0}, P_{-1}, d_{-1}^{g}, d_{-1}^{e}
\end{array}\right.
\end{gathered}
$$

Because $K_{t}$ and $N_{t}$ are given at time $t$, we can use $K_{t}^{e}=K_{t}-K_{t}^{g}$ and $L_{t}^{e}=N_{t}-L_{t}^{g}$. Denoting by $\lambda_{t}^{g}$ and $\lambda_{t}^{e}$ respectively the Lagrangian multipliers of the resources Constraints (5) and (6) by $\lambda_{t}^{g}$ and $\lambda_{t}^{e}$ respectively and by $\mu_{t}$ the Lagrangian multipliers of the dynamic of the stock of pollution (3), the Lagrangian can be written as follows

$\gamma^{-1} N_{-1} U_{-1}+\sum_{t=0}^{+\infty} \gamma^{t}\left\{\begin{array}{c}N_{t} U_{t}+\lambda_{t}^{g}\left[F^{g}\left(K_{t}^{g}, L_{t}^{g}, Z_{t}\right)-N_{t} c_{t}^{g}-N_{t-1} d_{t}^{g}-K_{t+1}\right] \\ +\lambda_{t}^{e}\left[F^{e}\left(K_{t}-K_{t}^{g}, N_{t}-L_{t}^{g}, E_{t}\right)-N_{t} c_{t}^{e}-N_{t-1} d_{t}^{e}-Z_{t}\right] \\ +\mu_{t}\left[P_{t}-(1-h) P_{t-1}-m\left(E_{t}\right)\right]\end{array}\right\}$

The first-order conditions associated to with that the problem are the following:

1. for the final consumption in the first period

$$
U_{c_{t}^{g}}=\lambda_{t}^{g} \text { and } U_{c_{t}^{e}}=\lambda_{t}^{e}
$$


2. for final consumption in the second period

$$
\frac{1}{\gamma} U_{d_{t}^{g}}=\lambda_{t}^{g} \text { and } \frac{1}{\gamma} U_{d_{t}^{e}}=\lambda_{t}^{e}
$$

3. for energy use, $Z_{t}$, emissions level $E_{t}$,

$$
\lambda_{t}^{g} F_{Z_{t}}^{g}=\lambda_{t}^{e}, \lambda_{t}^{e} F_{E_{t}}^{e}=\mu_{t} m_{E_{t}}
$$

where $F_{Z_{t}}^{g}$ is the derivative of $F^{g}\left(K_{t}^{g}, L_{t}^{g}, Z_{t}\right)$ with respect to the third argument, and similarly for $F_{E_{t}}^{e}$ and $m_{E_{t}}$. The arbitrage conditions for capital and labor among between the two productive sectors of the economy are as follows,

$$
\lambda_{t}^{g} F_{K_{t}^{g}}^{g}=\lambda_{t}^{e} F_{K_{t}^{e}}^{e} \text { and } \lambda_{t}^{g} F_{L_{t}^{g}}^{g}=\lambda_{t}^{e} F_{L_{t}^{e}}^{e} .
$$

The dynamics of the shadow prices are obtained by differentiating the Lagrangian with respect to $K_{t+1}$ and $P_{t}, \forall t \geq 0$,

$$
\lambda_{t}^{g}=\gamma \lambda_{t+1}^{e} F_{K_{t+1}^{e}}^{e}\left(K_{t+1}-K_{t+1}^{g}, N_{t+1}-L_{t+1}^{g}, E_{t+1}\right)
$$

and

$$
\mu_{t}=\gamma \mu_{t+1}(1-h)+N_{t} \frac{\partial U_{t}}{\partial P_{t}}+\frac{N_{t-1}}{\gamma} \frac{\partial U_{t-1}}{\partial P_{t}} .
$$

The transversality condition (Michel, 1990) is

$$
\lim _{t \rightarrow+\infty} \gamma^{t}\left(\lambda_{t}^{g} K_{t+1}+\mu_{t} P_{t}\right)=0
$$

These FOCs are used to derive the optimal arbitrage conditions discussed in Section 3.2. Condition $\mathcal{C} .1$ (optimal allocation of production factors allocation) is obtained from the ratio $\lambda_{t}^{g} / \lambda_{t}^{e}$. Condition $\mathcal{C} .2$ (trade-offs between consumptions over the life cycle) comes from the dynamic equation of $\lambda_{t}^{e}$.

\section{References}

[1] Allais M., 1947, Economie et Intérêt, Imprimerie Nationale.

[2] Atkinson A., A. Sandomo, 1980. "Welfare Implications of the taxation of savings", Economic Journal, 90, 529-549. 
[3] Bovenberg A.L. and R.A. De Mooij, 1994. "Environmental levies and distortionary taxation', American Economic Review, 84, 1085-1089.

[4] Coase M.A., 1960, "The Problem of Social Cost", Journal of Law and Economics, 3, 1-44.

[5] De La Croix, D., Ph. Michel, 2002. A Theory of Economic Growth: Dynamics and Policy in Overlapping Generations, Cambridge University Press.

[6] Diamond P.A. 1965. "National Debt in a Neoclassical Growth Model", American Economic Review, 30, 657-740.

[7] Ellerman A.D., F.J. Convery and Ch. de Perthuis, 2010. Pricing Carbon. The European Emission Trading Scheme, Cambridge University Press.

[8] Galor O., 1992. "A Two-sector Overlapping Generations Model: a Global Characterization of the Dynamical System", Econometrica, 60, 1351-1386.

[9] Goulder L.H., 2002. "Mitigating the Adverse Impacts of $\mathrm{CO}_{2}$ Abatement Policies on Energy-Intensive Industries", RFF Discussion Paper 0222.

[10] Hahn F. and R. Solow 1997. A Critical Essay on Modern Macroeconomic Theory. MIT Press.

[11] International Energy Agency, 2005. Act Locally, Trade Globally, Emissions Trading for Climate Policy. OECD/IEA, Paris.

[12] Jouvet P.A., Ph. Michel and G. Rotillon, 2005. "Optimal Growth with Pollution : How to Use Pollution Permits", Journal of Economic Dynimics and Control, 29, 1597-1609.

[13] Jouvet P.A., Ph. Michel and G. Rotillon, 2010. "Competitive Markets for Pollution Permits: Impact on Factor Income and International Equilibrium", Environmental Modelling and Assessment, 15, 1-11.

[14] Koutstaal P., 1997. Economic Policy and Climate Change: Tradeable Permits for Reducing Carbon Emissions, Edward Elgar Publishing Limited, UK. 
[15] Michel Ph., 1990. "Some Clarifications on Traversality Conditions", Econometrica, 58, 705-723.

[16] Montgomery D.W., 1972. "Markets in Licenses and Efficient Pollution Control Programs", Journal of Economic Theory, 5, 395-418.

[17] Ono T., 2002. "Effects of Emission Permits on Growth and the Environment", Environmental and Resource Economics, 21, 75-87.

[18] Parry I.W.H., R.C. Williams, and L.H. Goulder, 1999. "When Can Carbon Abatement Policies Increase Welfare? The Fundamental Role of Distorted Factor Markets" Journal of Environmental Economics and Management, 37, 52-84.

[19] Stavins R.N., 1998. "What Can We Learn from the Grand Policy Experiment? Lessons from $\mathrm{SO}_{2}$ Allowance Trading", Journal of Economic Perspectives, 12(3), 69-88.

[20] Verbruggen A., 2008. "Windalls profits and other profits", Energy Policy, 36(9), 3249-3251.

[21] Weitzman R., 1974. "Prices vs. quantities", Review of Economic Studies, 41, 477-491.

[22] Samuelson, P., 1975. "Optimum Social Security in a life-cycle growth model", International Economic Review, 16, 539-544.

[23] Sala-i-Martin X., 1996. "A Positive Theory of Social Security", Journal of Economic Growth, 1, 277-304.

[24] Solow R., 1986. "On the Intergenerational Allocation of Resources", Scandinavian Journal of Economics, 88, 141-149. 


\section{Recent titles}

\section{CORE Discussion Papers}

2010/17. Thierry BRECHET, Tsvetomir TSACHEV and Vladimir M. VELIOV. Markets for emission permits with free endowment: a vintage capital analysis.

2010/18. Pierre M. PICARD and Patrice PIERETTI. Bank secrecy, illicit money and offshore financial centers.

2010/19. Tanguy ISAAC. When frictions favour information revelation.

2010/20. Jeroen V.K. ROMBOUTS and Lars STENTOFT. Multivariate option pricing with time varying volatility and correlations.

2010/21. Yassine LEFOUILI and Catherine ROUX. Leniency programs for multimarket firms: The effect of Amnesty Plus on cartel formation.

2010/22. P. Jean-Jacques HERINGS, Ana MAULEON and Vincent VANNETELBOSCH. Coalition formation among farsighted agents.

2010/23. Pierre PESTIEAU and Grégory PONTHIERE. Long term care insurance puzzle.

2010/24. Elena DEL REY and Miguel Angel LOPEZ-GARCIA. On welfare criteria and optimality in an endogenous growth model.

2010/25. Sébastien LAURENT, Jeroen V.K. ROMBOUTS and Francesco VIOLANTE. On the forecasting accuracy of multivariate GARCH models.

2010/26. Pierre DEHEZ. Cooperative provision of indivisible public goods.

2010/27. Olivier DURAND-LASSERVE, Axel PIERRU and Yves SMEERS. Uncertain long-run emissions targets, $\mathrm{CO}_{2}$ price and global energy transition: a general equilibrium approach.

2010/28. Andreas EHRENMANN and Yves SMEERS. Stochastic equilibrium models for generation capacity expansion.

2010/29. Olivier DEVOLDER, François GLINEUR and Yu. NESTEROV. Solving infinite-dimensional optimization problems by polynomial approximation.

2010/30. Helmuth CREMER and Pierre PESTIEAU. The economics of wealth transfer tax.

2010/31. Thierry BRECHET and Sylvette LY. Technological greening, eco-efficiency, and no-regret strategy.

2010/32. Axel GAUTIER and Dimitri PAOLINI. Universal service financing in competitive postal markets: one size does not fit all.

2010/33. Daria ONORI. Competition and growth: reinterpreting their relationship.

2010/34. Olivier DEVOLDER, François GLINEUR and Yu. NESTEROV. Double smoothing technique for infinite-dimensional optimization problems with applications to optimal control.

2010/35. Jean-Jacques DETHIER, Pierre PESTIEAU and Rabia ALI. The impact of a minimum pension on old age poverty and its budgetary cost. Evidence from Latin America.

2010/36. Stéphane ZUBER. Justifying social discounting: the rank-discounting utilitarian approach.

2010/37. Marc FLEURBAEY, Thibault GAJDOS and Stéphane ZUBER. Social rationality, separability, and equity under uncertainty.

2010/38. Helmuth CREMER and Pierre PESTIEAU. Myopia, redistribution and pensions.

2010/39. Giacomo SBRANA and Andrea SILVESTRINI. Aggregation of exponential smoothing processes with an application to portfolio risk evaluation.

2010/40. Jean-François CARPANTIER. Commodities inventory effect.

2010/41. Pierre PESTIEAU and Maria RACIONERO. Tagging with leisure needs.

2010/42. Knud J. MUNK. The optimal commodity tax system as a compromise between two objectives.

2010/43. Marie-Louise LEROUX and Gregory PONTHIERE. Utilitarianism and unequal longevities: A remedy?

2010/44. Michel DENUIT, Louis EECKHOUDT, Ilia TSETLIN and Robert L. WINKLER. Multivariate concave and convex stochastic dominance.

2010/45. Rüdiger STEPHAN. An extension of disjunctive programming and its impact for compact tree formulations.

2010/46. Jorge MANZI, Ernesto SAN MARTIN and Sébastien VAN BELLEGEM. School system evaluation by value-added analysis under endogeneity. 


\section{Recent titles}

\section{CORE Discussion Papers - continued}

2010/47. Nicolas GILLIS and François GLINEUR. A multilevel approach for nonnegative matrix factorization.

2010/48. Marie-Louise LEROUX and Pierre PESTIEAU. The political economy of derived pension rights.

2010/49. Jeroen V.K. ROMBOUTS and Lars STENTOFT. Option pricing with asymmetric heteroskedastic normal mixture models.

2010/50. Maik SCHWARZ, Sébastien VAN BELLEGEM and Jean-Pierre FLORENS. Nonparametric frontier estimation from noisy data.

2010/51. Nicolas GILLIS and François GLINEUR. On the geometric interpretation of the nonnegative rank.

2010/52. Yves SMEERS, Giorgia OGGIONI, Elisabetta ALLEVI and Siegfried SCHAIBLE. Generalized Nash Equilibrium and market coupling in the European power system.

2010/53. Giorgia OGGIONI and Yves SMEERS. Market coupling and the organization of countertrading: separating energy and transmission again?

2010/54. Helmuth CREMER, Firouz GAHVARI and Pierre PESTIEAU. Fertility, human capital accumulation, and the pension system.

2010/55. Jan JOHANNES, Sébastien VAN BELLEGEM and Anne VANHEMS. Iterative regularization in nonparametric instrumental regression.

2010/56. Thierry BRECHET, Pierre-André JOUVET and Gilles ROTILLON. Tradable pollution permits in dynamic general equilibrium: can optimality and acceptability be reconciled?

\section{Books}

J. GABSZEWICZ (ed.) (2006), La différenciation des produits. Paris, La découverte.

L. BAUWENS, W. POHLMEIER and D. VEREDAS (eds.) (2008), High frequency financial econometrics: recent developments. Heidelberg, Physica-Verlag.

P. VAN HENTENRYCKE and L. WOLSEY (eds.) (2007), Integration of AI and OR techniques in constraint programming for combinatorial optimization problems. Berlin, Springer.

P-P. COMBES, Th. MAYER and J-F. THISSE (eds.) (2008), Economic geography: the integration of regions and nations. Princeton, Princeton University Press.

J. HINDRIKS (ed.) (2008), Au-delà de Copernic: de la confusion au consensus ? Brussels, Academic and Scientific Publishers.

J-M. HURIOT and J-F. THISSE (eds) (2009), Economics of cities. Cambridge, Cambridge University Press.

P. BELLEFLAMME and M. PEITZ (eds) (2010), Industrial organization: markets and strategies. Cambridge University Press.

M. JUNGER, Th. LIEBLING, D. NADDEF, G. NEMHAUSER, W. PULLEYBLANK, G. REINELT, G. RINALDI and L. WOLSEY (eds) (2010), 50 years of integer programming, 1958-2008: from the early years to the state-of-the-art. Berlin Springer.

\section{CORE Lecture Series}

C. GOURIÉROUX and A. MONFORT (1995), Simulation Based Econometric Methods.

A. RUBINSTEIN (1996), Lectures on Modeling Bounded Rationality.

J. RENEGAR (1999), A Mathematical View of Interior-Point Methods in Convex Optimization.

B.D. BERNHEIM and M.D. WHINSTON (1999), Anticompetitive Exclusion and Foreclosure Through Vertical Agreements.

D. BIENSTOCK (2001), Potential function methods for approximately solving linear programming problems: theory and practice.

R. AMIR (2002), Supermodularity and complementarity in economics.

R. WEISMANTEL (2006), Lectures on mixed nonlinear programming. 